\title{
A opressão metalingüística em Debaixo da Ponte Preta, de Dalton Trevisan
}

\author{
Marcio Renato Pinheiro da SILVA \\ CAPES/ UNESP de São José do Rio Preto
}

Palavras-chave: conto brasileiro contemporâneo; Dalton Trevisan; relato jurídico-policial; intertextualidade; semiótica.

Resumo: Com base na teoria semiótica, pretende-se analisar a intertextualidade entre o conto Debaixo da Ponte Preta, de Dalton Trevisan, e o relato jurídicopolicial, especialmente, a maneira como o conto de Trevisan desloca a vontade de verdade inerente ao relato e os interesses de cada depoente, ressaltando, dentre outras coisas, o papel do texto policial como cúmplice da opressão.

Abstract: Based on semiotic theory, this paper intends to analyze the intertextuality between the short story Debaixo da Ponte Preta (Down the Black Bridge), by Dalton Trevisan, and the policial report, mainly, the way how Trevisan's short story displaces the will of truth inherent in the policial report and each deponents' interest, emphasizing, among other things, the role of the policial text as accomplice of oppression.

Resumen: Con base en la teoría semiótica, intentase analizar la intertextualidad entre el cuento Debaixo da Ponte Preta (Debajo de la Puente Negra), de Dalton Trevisan, y el relato policial, especialmente, la manera como el cuento de Trevisan disloca la voluntad de verdad inherente al relato e los intereses de cada deponente, resaltando, entre otras cosas, el papel del texto policial como cómplice de la opresión.

SIGNUM: Estud. Ling., Londrina, n. 5, p. 275-285, dez. 2002 275 


\section{Introdução}

Em uma relação intertextual, isto é, de interação semiótica entre textos, as estruturas textuais que se inter-relacionam são ou particulares, ou gerais; ou da ordem da mensagem, ou da do código (Frow, 1990). Isto significa que um determinado texto tem, como intertexto, um texto específico ou normas culturais e ideológicas, convenções de gênero e de estilo, séries conotativas coletivas, clichês, fórmulas, provérbios etc. (Frow, 1990). Nos dois casos, é importante reconstruir os códigos culturais que são concretizados e/ou contestados nos textos (Frow, 1990), para que as possíveis significações da relação intertextual se revelem.

Em Debaixo da Ponte Preta, do contista paranaense Dalton Trevisan, o intertexto não é um texto específico, mas um, por assim dizer, tipo de texto específico, o relato jurídico-policial (chamado, também, de boletim de ocorrência). Como o estudo proposto aqui parte da hipótese de que Debaixo da Ponte Preta desloca elementos inerentes ao relato jurídico-policial (a vontade de verdade e os interesses dos depoentes), algumas considerações sobre este, mais precisamente, sobre seu possível funcionamento semiótico, devem preceder uma reflexão sobre aquele.

\section{Esboço do funcionamento semiótico do relato jurídico-policial}

O relato jurídico-policial visa uma espécie de reconstituição discursiva de um evento anterior. Este evento vem à tona por meio do registro de queixa, feito, geralmente, por um actante que se diz vítima de um delito cometido por outrem. O relato tem, aí, a função de registrar o depoimento de todos os actantes envolvidos para que o ocorrido seja averiguado pelas autoridades competentes (faz̧er-saber). Com base nesta averiguação, decidese pelo procedimento mais condizente à manutenção do bem-estar social e da vigência das leis (um fazer-dever como, por exemplo, instauração de inquérito, prisão preventiva, arquivamento etc.). 
Desta breve caracterização, convém ressaltar dois aspectos. Primeiramente, o fazer-saber do relato jurídico-policial é nutrido por uma "vontade de verdade" (Foucault, 1995), que o justifica socialmente, como se ele fosse um possível acesso ao que aconteceu realmente; como se ele, no entrelaçamento dos depoimentos, pudesse revelar a fenda em que assiste a verdade obliterada. Impulsionado por esta vontade, o enunciador lança mão de determinados artifícios para articular um efeito de realidade/ de referente (Barros, 2001), que confere veridição ao discurso e simula sua objetividade. Alguns exemplos destes artifícios são a) narrador heterodiegético (Genette, 1972), que se esquiva de qualquer papel actancial; b) focalização z̧ero (Genette, 1972), limitada ao dito pelos actantes em seus depoimentos, sem fazer qualquer conjuntura acerca de sua vida interior, c) escolha lexical que prioriza substantivos concretos e verbos no pretérito do modo indicativo e evita expressões adjetivas; d) ancoragem (Barros, 2001) tão definida quanto possível for; e) discurso indireto, em que as idiossincrasias discursivas (léxico, sintaxe etc.) dos depoentes-actantes são niveladas pelas do narrador, as quais correspondem aos quatro artifícios citados anteriormente ${ }^{1}$. Resulta, daí, um discurso coercivo, que tenta excluir a subjetividade e o desejo, que proíbe manifestações capazes de pôr em xeque a objetividade, o fazer-dever, enfim, desestabilizar a sanção proferida pela sociedade e pelo poder judiciário em nome da verdade e da justiça.

O segundo aspecto diz respeito às particularidades da enunciação deste tipo de texto. Um relato jurídico-policial, em sua materialidade (linguagem verbal escrita disposta em papel), é um enunciado surgido da tomada de nota dos depoimentos, a qual pretende esclarecer o que, de fato, aconteceu (conjunção/disjunção com um saber). Mas o acontecido, o evento precedente que se pretende esclarecer, é, também, uma enunciação,

\footnotetext{
${ }^{1}$ Esta desembreagem enunciva em terceira pessoa do relato jurídico-policial projeta um narrador bastante próximo do observador, que é, "como o narrador, delegado da enunciação, mas não lhe cabe contar a história e sim determinar um ou mais pontos de vista sobre o discurso e dirigir seu desenrolar" (Barros, op. cit., p. 58). A despeito desta semelhança, opta-se, aqui, por não considerar o delegado da enunciação como observador devido a o narrador apresentar a sua versão dos depoimentos com base nos artifícios mencionados, adaptar estes depoimentos ao jargão do relato.
} 
ainda que, dela, não tenha resultado enunciado algum, senão, hipoteticamente, meras pistas. E é por não ter resultado em enunciado algum que o relato-policial é feito: é, portanto, uma enunciação sobre uma outra enunciação.

Esta segunda enunciação é motivada por um (ou mais) actante-acusante (A1), que se diz vítima de outro sujeito (ou mais), o actante-acusado (A2). Aí, há a possibilidade de os dois actantes entrarem em conflito: A1 se diz inocente e acusa A2 de ser culpado; A2 se diz não-culpado e acusa A1 de ser não-inocente. Estas possíveis performances dos dois actantes justificam-se, pois, se, em tese, A1 quer justiça, quer firmar sua inocência, A2 quer safar-se da culpa e de eventuais penalidades por ter cometido algum delito.

Há uma ambivalência aí. O relato jurídico-policial, em sua função social, naquilo que o justifica, tem, como estruturas fundamentais, a verdade (eufórico) e a falsidade (disfórico). Mas, em sua enunciação, a performance dos actantes pode acenar a outras estruturas fundamentais, à inocência (eufórico) e à culpa (disfórico) precisamente. Ou seja, o bem-estar social e a manutenção da lei podem mesclar-se aos interesses de cada actante.

Assim sendo, convém averiguar as possíveis articulações das estruturas fundamentais relativas à função social do relato jurídico-policial e à performance, nele, dos actantes. No primeiro caso, há as seguintes combinações: verdade, mentira, não-verdade, não-mentira; no segundo, outras quatro: A1 inocente, A2 culpado, A1 não-inocente, A2 não-culpado. Considerando que, em sua função social, o relato jurídico-policial anseia a verdade, a combinação das duas estruturas fornece quatro possíveis verdades (A1 inocente, A2 culpado, A1 não-inocente, A2 não-culpado) que, por sua vez, possibilitam quatro percursos narrativos potencialmente verdadeiros (A1 é inocente, e A2, culpado; A1 é inocente, e A2, não-culpado; A1 é não-inocente, e A2, culpado; A1 é não-inocente, e A2, não-culpado) em meio a dezesseis possíveis. ${ }^{2}$

\footnotetext{
${ }^{2}$ Isso se não se considerar que, na verdade, a acusação de A1 não procede e, por isso, A2 deseje acusá-lo (por danos morais etc.), o que acarretaria mais quatro percursos narrativos potencialmente verdadeiros, perfazendo um total de oito potencialmente verdadeiros em meio a trinta e dois possíveis. $\mathrm{Ou}$, ainda, que há outros actantes-acusados envolvidos, cuja culpa e cuja inocência devem ser articuladas separadamente para, então, perfazer-se a quantidade de percursos narrativos potencialmente verdadeiros... e assim sucessivamente.
} 
Se um determinado acontecimento/delito sobre o qual se dá queixa tem, ao menos, dezesseis programas narrativos possiveis, dos quais quatro são verdadeiros potencialmente, qual dos quatro é, de fato, o verdadeiro? Seria o relato jurídico-policial, com seus métodos e convenções, capaz de descobrir a verdade em meio a tantas possibilidades? Essas são algumas das questões que Debaixo da Ponte Preta, de Dalton Trevisan, suscita.

\section{Debaixo da Ponte Preta, de Dalton Trevisan}

Debaixo da Ponte Preta segue as características do relato jurídico-policial já descritas. Logo em seu início, um actante se diz vítima de estupro, delito este cometido por vários outros actantes:

Noite de vinte e três de junho, Ritinha da Luz, dezesseis anos, solteira, prenda doméstica, ao sair do emprego, dirigiu-se à casa de sua irmã, atrás da Ponte Preta. $\mathrm{Na}$ linha do trem foi atacada por quatro ou cinco indivíduos, aos quais se reuniram mais dois. Então violada por um de cada vez e abandonada entre as moitas. Seu choro atraiu um guarda civil, que a conduziu até a delegacia.

A menina nunca tinha visto os homens, não sabia a que atribuir o assalto. Nem qual foi o primeiro, agarrada e derrubada, a cabeça coberta. Arrastada pelo chão, fortes dores nos seios e nas partes. Que não gritasse por socorro, barbaramente espancada. Apresentou-se com saia de seda preta e blusa vermelha de malha, sujas de lama. No corpo, além de muitas feridas, folha seca, grama e barro. A hora lá pelas dez ou onze (Trevisan, 1998, p. 76-77).

O depoimento de A1, a actante-acusante Ritinha, fornece boa parte dos dados relativos ao estupro, à enunciação anterior ao relato. São, ao todo, seis A2 os acusados de estupro (três soldados, Miguel, o guardião da estrada de ferro e um estudante). Há, ainda, duas testemunhas, o primo 
do estudante e outro garoto que observara tudo à distância e ajudou a identificar os acusados, já que Ritinha estivera com a cabeça coberta todo o tempo, além do guarda-civil, que encontrara a moça e a conduziu à delegacia.

Os depoimentos de A2 são apresentados, sucessivamente, logo após o de A1, cada qual dando a sua versão do ocorrido, formando uma estrutura espiralada, de círculos em torno de um mesmo acontecimento. Isso dificulta a construção de um percurso gerativo de sentido linear, pois a isotopia formada a partir de um depoimento é modificada pelo seguinte, em constante construção e desconstrução das possíveis significações.

A hipótese, levantada anteriormente, sobre a possibilidade de a performance dos actantes ter, como estruturas fundamentais, inocência versus culpa (e não verdade versus falsidade) confirma-se. Isso se dá com base nas possibilidades de existência modal (ser e parecer) articuladas à estrutura fundamental de inocência versus culpa. Não por acaso, todos os actantes-acusados tentam estruturar sua própria existência modal de maneira idêntica: "Pareço culpado, mas sou não-culpado". Aí, a dialética entre imanência e aparência vai ao encontro das estruturas fundamentais do relato jurídico-policial em sua função social (verdade versus falsidade, que pode corresponder à essência versus aparência) e, simultaneamente, aos interesses dos actantes-acusados no sentido de serem sancionados positivamente e não terem de ser coagidos em função do delito.

Observando os casos descritos acima, tem-se, por exemplo, que, Miguel (A2), foguista, quarenta anos, passava pelo local quando avistou três soldados e uma menina em atitude suspeita. Foi até lá e, auxiliado pelos soldados, violentou-a: "Miguel, arrependido do mau gesto, se oferece para casar com a menina [...] tão logo apronte os papéis do desquite, de momento é casado" (Trevisan, 1998, p. 77). Vê-se que, ao propor o (hipotético) casamento, este actante-acusado tenta forjar uma auto-imagem afim à benevolência. De maneira desdobrada, o depoimento de A2 tenta desestabilizar a inocência de A1: se ambos serão marido e mulher, o delito 
cometido é algo permitido dentro da instituição do casamento, o que o descaracteriza como delito.

Já Nelsinho, outro A2, estudante de treze anos, "se confessa contrariado, atribuindo sua atitude à pouca idade que tem, ações como a que praticou apenas servem para estragar o futuro de um jovem" (Trevisan, 1998, p. 78). Chega a ser irônica esta justificativa (infundada) da delinqüência, "que estraga o futuro de um jovem", por meio da "pouca idade" de A2.

Alfredo, Durval e Pereira são soldados e, também, actantes-acusados. Durval diz que a moça aceitara, de bom grado, entregar-se-lhe, pois "gostou de seu cabelo loiro e olho azul” (Trevisan, 1998, p. 78). Pereira confirma a versão de Durval, mas acrescenta que ele e Alfredo não tinham sido "convidados" pela moça e, por isso, violentaram-na. Durval e Pereira acrescentam um outro actante, o guardião da estrada de ferro, com quem, segundo eles, Ritinha não queria se relacionar. Isso irritou o guardião, que a tratou com violência e a estuprou. Vê-se que Durval articula sua nãoculpa e a não-inocência de Ritinha por meio da atribuição, a A1, de características semelhantes à de uma moça "fácil" e/ou prostituta. Este é, também, o álibi de Alfredo e Pereira: se a moça é "fácil" a ponto de ter aceitado a proposta de Durval, o delito de A2 pode ser amenizado; afinal, se alguém cometeu delito, se alguém violentou a moça, trata-se do guardião da estrada de ferro. Coincidentemente, o depoimento do guardião, daquele que parece ter cometido o delito, não é fornecido no texto, se é que houve.

Os depoimentos sugerem diferentes existências modais dos actantes, o que, conseqüentemente, resulta em percursos narrativos distintos: Ritinha se diz inocente e acusa todos A2 de serem culpados; Nelsinho se diz não-culpado e considera Ritinha inocente; os três soldados se dizem não-culpados, sendo Ritinha não-inocente em relação ao ocorrido entre ela e eles e inocente em relação ao entre ela e o guardião, o culpado cujo depoimento não é fornecido. Dada a função social do relato jurídico-policial, é lícito indagar sobre qual destes percursos seria o verdadeiro. Mas o conto não fornece tal resposta.

SIGNUM: Estud. Ling., Londrina, n. 5, p. 275-285, dez. 2002 
Aliás, pelo contrário: há outros dados que dificultam a definição sobre qual percurso seria o verdadeiro. Tratam-se de certas informações, que ocupam a parte final do relato, cujo fornecedor não é explicitado. Por exemplo, diz-se que Miguel fora afrontado por Ritinha e que, então, "Indignado, decidiu provar que era homem [...] para não ficar desmoralizado perante a família, [...] mas não praticou o ato, em vista do estado nervoso" (Trevisan, 1998, p. 80). Faz-se, também, um breve histórico de Ritinha: há um mês, fora deflorada por outro soldado; há quinze dias, era órfã de pai; sua patroa lhe fornece roupas velhas, não sem descontar o valor referente no ordenado.

Embora, como dito, não se possa precisar sua fonte, estas informações remetem ao narrador, dadas suas características lexicais, sintáticas etc. Não é comum este tipo de postura do narrador em um relato jurídico-policial, e menos ainda a maneira como o conto termina - "O guarda-civil Leocádio, ao passar debaixo da Ponte Preta, viu uma negrinha chorando" (Trevisan, 1998, p. 81). Aí, o relato do guarda-civil que levara Ritinha à delegacia é finalizado abruptamente, realçando a figura do actante-acusante em seu desolamento: além do choro, o estar "debaixo da Ponte Preta", funciona, denotativamente, como uma locução adverbial de lugar (a título de curiosidade, a Ponte Preta existe, realmente, na cidade de Curitiba), auxiliando a ancoragem, e, também, conotativamente, como figurativizaçãa do abandono e da penúria.

Embaralhamento das possíveis verdades, informações cujo informante/depoente não é delimitado, finalização abrupta de um depoimento, sobreposição da função poética sobre a referencial: tudo isto é infração às convenções do relato jurídico-policial, tudo isto abre a possibilidade de se tratar de uma transgressão ao relato. Ou seja, a verdade ambicionada pelo relato em sua função social e os interesses de cada actante cedem lugar à opressão sofrida por Ritinha. Dizendo de outro modo, o conto joga com as estruturas fundamentais de verdadeiro versus falso e inocência versus culpa, manipula-as, leva-as a um colapso para, então, realçar a opressão sofrida por Ritinha. 
Se assim o for, se a estrutura fundamental na qual se baseia o conto for, de fato, liberdade (eufórico) versus opressão (disfórico), Ritinha não é, apenas, um sujeito de estado (Barros, 2001), que sofre a ação de outrem. É, também, um ator (Barros, 2001) que, no nível do discurso, por meio do recebimento de um investimento semântico, cumpre um papel temático, figurativiza o oprimido. Da mesma forma, os actantes-acusados são, na verdade, os sujeitos do fazer, aqueles que exercem a ação, e, também, atores por cumprirem um papel temático, o de figurativizar o opressor.

Por este viés, o objeto de valor que Ritinha ambiciona é sua integridade física e moral/psicológica, com o qual, devido ao estupro, entra em disjunção. Já os actantes-acusados visam o prazer carnal e sexual. Mas, em momento algum, a possível satisfação pela consumação do ato sexual (forçado) é mencionada. Pelo contrário, o que se ressalta é a tentativa de se safar de uma sanção negativa, conotando, também, a disjunção em relação ao objeto de valor. Deste modo, se Ritinha perde seu objeto de valor, ninguém o ganha.

\section{Conclusão}

Debaixo da Ponte Preta é, portanto, um simulacro de relato jurídicopolicial que trata da opressão (disfórico), que a afirma, num gesto desdobrado, em nível tanto referencial quanto metalingüistico. Disto, abstrai-se alguns possíveis temas, todos interdependentes:

a) reificação da mulher, reduzindo-a a um corpo disponivel ao prazer dos homens. Isto é legitimado pelos estereótipos de macho e de (possível) prostituta;

b) a exclusão social, que vulnera os que, por ela, são atingidos, permitindo a exploração sexual e trabalhista dos excluídos por aqueles não-excluídos ou de menor grau de exclusão;

c) o racismo, que relega os negros à subalternância e à condição de explorados. A exploração da mão-de-obra braçal dos negros e a 
sujeição da mulher negra às relações sexuais casuais, sendo a branca "para casar", são estereótipos surgidos durante o colonialismo português no Brasil e bastante presentes na literatura brasileira dos períodos romântico e realista;

d) a crueldade e a violência das relações humanas nas periferias das grandes cidades, em que condições desumanas geram atitudes desumanas. Isto dá vazão à impossibilidade de diálogo entre as pessoas e de satisfação dos desejos, restando o silêncio e a frustração;

f) a cumplicidade dos órgãos oficiais em relação à opressão e à violência. Aí, as representações, por assim dizer, oficiais, aquelas a partir das quais se legitimam as ações sociais, obliteram, por meio de suas convenções burocráticas, os conflitos e tensões do relacionamento entre os cidadãos. Isto abre caminho à permissão de práticas, em princípio, condenáveis socialmente;

g) a impossibilidade de se conhecer o passado senão por meio de registros textuais, os quais se originam do lugar ocupado pelo enunciador. Este lugar, com seus determinantes sociais, políticos, históricos, econômicos, psíquicos, estéticos, ideológicos etc., impossibilita qualquer representação que se diga objetiva, onisciente, onipresente e onipotente;

h) a falência de valores abstratos/logocêntricos e pretensamente universais, tais como Bondade, Beleza, Verdade, Essência, Coisa-em-si etc. Pois, quando transpostos à práxis humana, revelam-se pretextos à dominação estética, política, histórica, social e ideológica;

i) concepção do fazer poético-literário como engajamento estético, como trabalho rigoroso com a linguagem. É deste trabalho que surgem os possíveis diálogos entre texto e contexto, entre ficção e sociedade. Isto põe em xeque concepções extremas e ingênuas, como arte pela arte (esteticismo) ou arte como instrumento de transformação/ revolução social (panfletarismo): de fato, o esteticismo 
configura uma atitude social, histórica e política, bem como o panfletarismo, uma estética. Se a literatura e as demais artes são fenômenos estéticos, implicam dimensões históricas, políticas, sociais etc., mas nem por isso os fatores estéticos devem estar em segundo plano. Pelo contrário: é, sobretudo, da poiésis e de sua execução/enunciação, da prática estética, que a arte se revela como prática, também, política, social e histórica.

\section{Bibliografia}

BARROS, D. L. P. Teoria semiótica do texto. 4. ed. São Paulo: Ática, 2001.

FOUCAULT, M. A ordem do discurso. Maringá: Eduem, 1995.

FROW, J. Intertextuality and Ontology. In: WORTON, M.; STILL, J. (Ed.). Intertextuality: Theories and Practices. Manchester: Manchester University Press, 1990. p. 45-55.

GENETTE, G. Discurs du récit: Essai de méthode. In: Figures III. Paris: Seuil, 1972. p. 65-273.

TREVISAN, D. Debaixo da Ponte Preta. In: - O vampiro de Curitiba. 20. ed. rev. Rio de Janeiro: Record, 1998. p. 76-81. 